unanesthetized cats. Science, 1956, 123 331-332.

LASHLEY, K. S., \& WADE, M. The Pavlovian theory of generalization. Psychological Review, 1946, 53, 72-87.

LYNN, R. Attention, arousal and the orienting reaction Oxford: Pergamon Press, 1966.

NÄATÄNEN, R. Selective attention and evoked potentials. Annales Academiae Scientiarum Fennicae, Series B, 151.1. Helsinki: Suomalainen Tiedeakatemia, 1967.

SARRIS, V. Adaptation-level theory: Two critical experiments on Helson's weighted average model. American Journal of Psychology, 1967, 80, 331-355.

SARRIS, V. Adaptation-level theory: Absolute or relative anchor effectiveness? Psychonomic Science, 1968, 13, 307-308.

SARRIS, V. Ankerreiz-Effekte bei Tonhohenbeurteilungen: Uberprufung des Adaptationsniveau-Modells. In M. Irle (Ed.), Bericht vom 26. Kongress der DGfP in Tubingen, 1968. Göttingen: Hogrefe, 1969. Pp. 399-405.

SARRIS, V. Anchoreffects in psychophysics: Tests on the adaptation-level model. In Reports of the XIX International Congress of
Psychology, London, 1969. In press, a

SARRIS, V. Wahrnehmung und Urteil: Bezugssystemeffekte in der Psychophysik. Gottingen: Hogrefe, in press.

SARRIS, V., TEWS, B., \& SCHONPFLUG, W. GSR and the anchoring of pitch judgments. Psychonomic Science, in press.

THOMPSON, R. F. Foundation of physiological psychology. New York: Harper \& Row, 1967.

WACHTEL, P. $\mathcal{L}$. Conceptions of broad and narrow attention. Psychological Bulletin, $1967,68,417-429$.

WORDEN, F. G. Attention and auditory electrophysiology. In E. Stellar and J. M. Sprague (Eds), Progress in physiological psychology. Vol. 1. New York: Academic Press, 1966. Pp. 45-116. NOTE

1. In addition to the main investigation reported here, 23 students served as $S s$ in an experiment to study (1) the effect of anchor frequency per se (without series stimuli), (2) the effect of instruction, and (3) the effect of stimulus-series variation on the auditory evoked responses. A full report of the corroborating results from these control experiments is given elsewhere (Sarris, in press b).

\title{
Rate of simple motor responding as a function of differential outcomes and the actual and implied presence of a coactor*
}

\author{
D. W. CARMENT \\ McMaster University, Hamilton, Ont., Canada
}

Male Ss performed a simple motor task, half alone and half coacting, under a VR 15 reinforcement schedule. Half of the coactors were paired with another $S$ on the same schedule and half with another S on a VR 5 schedule. Those performing alone could see the total reward that ostensibly had been obtained by a "previous subject." In half the cases, this "previous subject" had been on a VR 15 schedule and for the remainder on a VR 5 schedule. It was found that responding was highest among solitary Ss with lower outcomes and coactors with equal outcomes. Coactors with lower outcomes were intermediate and solitary Ss with equal outcomes responded most slowly. The importance of differential rewards and the nature of performance standards are noted.

A considerable amount of evidence has accumulated (reviewed by Zajonc, 1965,

*This research was supported by Grant No. PA0332 from the National Research Council of Canada and a grant from the Department of Labour, Government of Canada. Thanks are due Miss Judythe Little and Mr. James Alcock for their assistance. facilitated if the others present appear disinterested and unaware of the S's output (Cottrell, 1968). As Cottrell points out, these results suggest that the effects of coaction are dependent on the S's feeling that his performance in some way is being evaluated or appraised. This implies that the presence of a coactor or an audience, per se, does not enhance performance.

The experiment reported here was designed to explore this supposition. The performance of Ss alone, but aware of how a previous "subject" had performed, was contrasted with the performance of coacting Ss. Half of the Ss were paired with real or implied coactors with equal outcomes and the remainder with real or implied coactors whose outcomes were three times greater. Thus, in terms of evaluation, some Ss were led to believe that their performance was equal to that of their comparison, whereas others ostensibly performed much worse.

\section{SUBJECTS AND DESIGN}

The Ss were 40 male undergraduates chosen at random from an introductory psychology course. They were assigned randomly to four experimental conditions so that there were $10 \mathrm{Ss}$ in each condition. All Ss performed a simple motor task on a VR 15 schedule of "reinforcement." Two of the conditions included a coactor. In one of these, the coactor also was on a VR 15 schedule (coacting 15) and in the other he was on a VR 5 schedule (coacting 5). The first was intended to indicate equal levels of performance and the second that the $S$ was not performing as well as the other participant. In another two conditions, each $\mathrm{S}$ was alone but aware of the pay-off ostensibly obtained by a previous "subject." Half of these "previous subjects" had been on a VR 15 schedule (alone 15) and half on a VR 5 schedule (alone 5).

The four groups form a factorial design with two between-S factors and one within-S factor (solitary vs coacting, equal vs lower outcome, and time).

The dependent variable was the number of responses made each minute. A session lasted $5 \mathrm{~min}$.

\section{APPARATUS AND PROCEDURE}

The apparatus used was a modified Gerbrands-Lindsley conditioning panel connected to standard programming and timing units in an adjoining room. Briefly, the panel consists of two levers that can be pulled out and that are returned by an adjustable tension spring to their original position. Below each lever was a chute for the delivery of reinforcements and above each lever a counter was placed that accumulated the number of reinforcements each $S$ obtained. The reinforcements, in this case ball bearings, were placed by the $S$ 


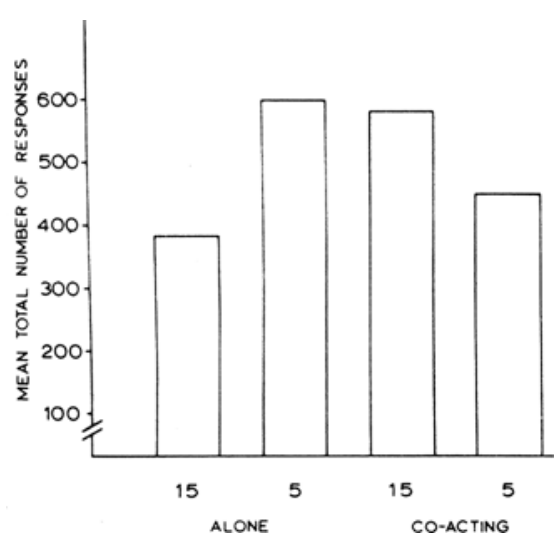

Fig. 1. Mean total number of responses as a function of outcome and coaction.

in transparent tubes beside the plungers as they were received. Thus a $S$ would be aware, visually and numerically, of the number of reinforcements both he and the other obtained.

Reinforcements were delivered to the $S$ on a VR 15 schedule. In the coacting conditions the other participant was on either a VR 15 or a VR 5 schedule. In the alone situation, the counter was preset and a number of ball bearings placed in the tubes to represent the average obtained by Ss in previous experiments who had been on either a VR 5 or a VR 15 schedule.

The Ss were brought to the experimental room and those in the alone-5 and alone- 15 conditions were instructed: "Would you please come over here and sit down in front of this side of the panel because we haven't had time to take these out from the last fellow who was here. Adjust your chair so that you can comfortably reach the lever and the top of these tubes. Fine. This experiment is concerned with some aspects of coordination. We are going to ask you to do a task which involves pulling out this lever. Each time you do it correctly, you will receive a ball bearing. All you have to do is pull the lever out like this and release it. You can pull it out as fast or slow as you like, as long as you don't hold it out. A ball bearing will drop down here whenever you are correct. Whenever one drops down pick it up and put it in the inside tube here. This will help keep track of how many you've made. When one tube gets full start on the next one. Any questions? O.K. Start to work as soon as these lights come on and stop when they go off. They will come on in a moment."

The first three sentences were omitted in the instructions to the Ss in the coacting conditions, and the following was added: "One last thing, there is no connection between the two sides of this panel. What one of you does, does not affect the other. Wo are simply running two people at a time

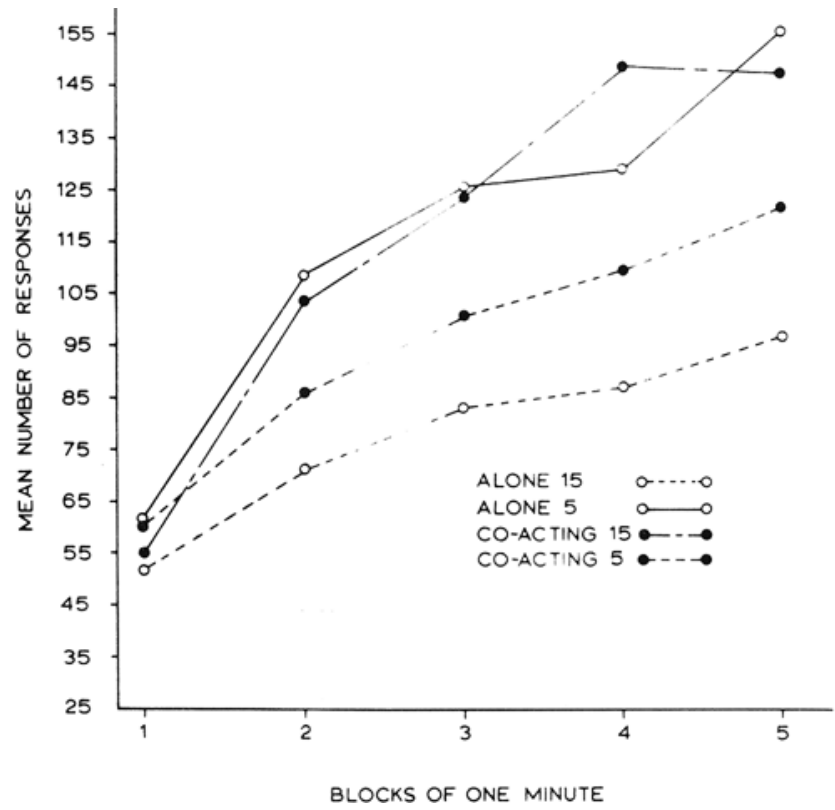

Fig. 2. Mean of number of responses each minute as a function of outcome and coaction.

to get through the experiment faster. Please don't talk to each other while you are working."

\section{RESULTS}

The analysis of variance resulted in a significant Between-Ss Coaction by Comparison interaction $(F=6.16$, $\mathrm{df}=1 / 36, \mathrm{p}<.025)$, which is illustrated in Fig. 1. It can be seen that $S$ s paired with coactors with similar outcomes make more responses than $S$ s paired with coactors whose outcomes are greater. The reverse of this appears when the Ss are alone.

The trends over time are plotted in Fig. 2. There is a significant increase in responding as the session progresses $(F=36.77, d f=4 / 144, p<.001)$ and $a$ significant interaction between time, coaction, and comparison $(\mathrm{F}=3.79$, $\mathrm{df}=4 / 144, \mathrm{p}<.01)$. Ss in the coacting-15 and alone-5 groups respond at about the same rate throughout the experimental session. Ss in the coacting-5 group make substantially fewer responses and those in the alone-15 condition the least.

\section{DISCUSSION}

These results emphasize the importance of relative rewards as a determinant of dyadic performance. This is not surprising in view of the considerable research devoted to the effects of "inequity" (Adams, 1963; Lawlor, 1968) that leads to the prediction that underpaid $S$ s should work harder than those paid equitably. In the present experiment, this occurs only if the $S$ is alone, whereas the output of the underpaid coacting $S s$ is less than that of coactors with equal outcomes. This implies that the nature of the comparison or standard must be taken into consideration.
If the standard is fixed, as in the alone-5 condition. the $\mathrm{S}$ is motivated to work harder, but if the comparison is changing and the other participant remains continually ahead, as in the coacting- 5 condition, the effect is debilitating and performance is reduced. These results are not in accord with Swingles's (1969) finding that the performance of consistent losers in races was enhanced when they lagged behind the winner by a considerable margin. Cottrell's (1968) contention, that coaction effects are dependent on the S's feeling that his performance is being evaluated, must be extended to take into consideration the form the evaluation takes.

\section{REFERENCES}

ADAMS. J. S. Toward an understanding of inequity. Journal of Abnormal \& Social Psychology, 1963. 67, 422-436.

COTTRELL. N. B. Performance in the presence of other human beings: Mere presence. audience. and affiliation effects. In E. C. Simmel. R. A. Hoppe, and G. A. Milton (Eds.). Social facilitation and imitative behavior. Boston: Allyn \& Bacon, 1968. Pp. 91-110.

DASHIELL. J. E. An experimental analy sis of some group effects. Journal of Abnormal \& Social Psychology. 1930. 25, 190-199.

LAWLOR. E. E. Equity theory as a predictor of productivity and work quality. Psychological Bulle tin. 70. 1968, 596-610.

SWINGLI: P. G. Effects of the win-loss ratio and challenge on speed in a two person lever-pressing race. Journal of Experimental Psychology. 1969. 80, 542-547.

ZAJONC.R. B. Social facilitation. Science. 1965 149. 269-274.

ZAJOXC. R. B. Social psychology. $A n$ experimental approach. Belmont, Calif: Wadsworth. 1966. 